\title{
Synchronous Generator Modelling and Analysis for a Microgrid in Autonomous and Grid Connected Mode
}

\author{
S.Jaganathan \\ Assistant professor \\ Electrical Engineering \\ RVS College of Engg and Tech \\ Coimbatore, Tamilnadu, India.
}

\author{
Dr.S.Palaniswami \\ Professor \\ Electrical Engineering \\ Government College of Tech, \\ Coimbatore, Tamilnadu, India
}

\author{
R.Adithya \\ M.Naresh Kumaar \\ UG SCHOLARS \\ RVS College of Engg and Tech \\ Coimbatore, Tamilnadu, India.
}

\begin{abstract}
Distributed generation is constructed on the basis of decentralized generation of electricity close to consumption sites using Distributed Generation (DG) sources. An optimized way to utilize the emerging potential of the distributed generation is to consider generation and its associated loads as a subsystem called "microgrid". A microgrid comprises of multiple DG units in close electrical proximity to one another. During disturbances the generation and the corresponding loads can separate from the distribution system to isolate the microgrid's loads from the disturbance and thereby maintaining the service without harming the integrity of transmission grid.
\end{abstract}

This work elaborates in detail the modeling and analysis of the Synchronous Generator that is connected to the microgrid which is the considered as one of the DGs. The modeling has been done in MATLAB/SIMULINK by integrating all the sub-models which include exciter, turbine and governor and the electrical part.

Index Terms - Modeling, Simulation, Analysis.

Keywords - Microgrid, Synchronous generator, Load controller, VAR compensator, Distribution generation.

\section{INTRODUCTION}

A better way to realize the emerging potential of distributed generation is to take a system approach which views generation and its associated loads as a subsystem or a 'microgrid'. During disturbances, the generation and the corresponding loads can separate from the distribution system to isolate the microgrid's loads from the disturbance (and thereby maintaining service) without harming the transmission grid's integrity. This approach allows for local control of distributed generation thereby reducing or eliminating the need for central dispatch. Intentional islanding of generation and loads has the potential to provide a higher local reliability than that provided by the power system as a whole. [1] Distributed power generation system is emerging as a complementary infrastructure is constructed on the basis of decentralized generation of electricity close to consumption sites using distributed generation (DG) sources [2]. The increase in DG penetration depths and the presence of multiple DG units in electrical proximity to one another have brought about the concept of microgrid.
A microgrid is a portion of a power system which includes one or more DG units capable of operating either in parallel with or independent from a large utility grid while providing continuous power to multiple loads and end users [3]. The idea supporting the formation of the microgrid is that a paradigm consisting of multiple generators and aggregated loads is far more reliable and economical than the single generator serving a single load. An autonomous microgrid is formed when an electrical region capable of autonomous operation is islanded from the remainder of the grid [4] [10]; E.g., A distribution substation along with its feeders that service both DG units and local load. Formation of an autonomous microgrid, due to an islanding process, can be caused by disturbances, such as a fault or as a result of pre planned switching events after disconnection from the main grid experiences transients.

There can be any number of distributed generators connected to the microgrid. The more the number of distributed generators, more is the local reliability and the power quality of the system [11]. Synchronous generator which is one of the best known sources of electric power is taken and all the procedures needed to connect it to the microgrid are employed. This includes the modeling of the generator in various modes i.e the autonomous mode where the generator is islanded from the grid and the grid connected mode where the generator serves the local load. For the autonomous mode, each part of the machine such as the exciter, turbine, governor, etc... have been modeled. After the modeling of the generator, various parameters such as the terminal voltage, current, grid voltage, current and fault voltages have been observed at various conditions. The knowledge of the parameters enhances the possibility to improve the overall efficiency of the synchronous generator and hence the overall power quality of the microgrid.

\subsection{SYSTEM MODEL}

The proposed model of synchronous generator is one of the distributed generation of the 2DG microgrid system as shown in Fig.1. The ratings of the synchronous DG are 5MVA and $15 \mathrm{kV}$.The synchronous DG is equipped with turbine and governor system, exciter system and a steady state system. This DG is then connected with a load controller and VAR compensator to the microgrid [5]. This DG is connected to the microgrid for real power support. The load controller and VAR compensator is used for reactive power compensation and stability of the system. 


\begin{tabular}{|l|lll|ll|}
\hline \multicolumn{7}{|c|}{ DG Specification $\mathrm{S}_{\mathrm{b}}=5 \mathrm{MVA}, \mathrm{V}_{\mathrm{b}}=15 \mathrm{kV}$} \\
\hline $\mathrm{R}_{\mathrm{a}}$ & .0052 & (p.u) & $\mathrm{X}_{\mathrm{is}}$ & 0.02 & (p.u) \\
\hline $\mathrm{X}_{\mathrm{d}}$ & 2.86 & (p.u) & $\mathrm{X}_{\mathrm{q}}$ & 2.0 & (p.u) \\
\hline $\mathrm{X}_{\mathrm{d}}{ }^{\prime}$ & 0.7 & (p.u) & $\mathrm{X}_{\mathrm{q}}{ }^{\prime}$ & 0.85 & (p.u) \\
\hline $\mathrm{X}_{\mathrm{d}}{ }^{\prime}$ & 0.22 & (p.u) & $\mathrm{X}_{\mathrm{q}}{ }^{\prime}$ & 0.2 & (p.u) \\
\hline $\mathrm{T}_{\mathrm{do}}{ }^{\prime}$ & 3.4 & (p.u) & $\mathrm{T}_{\mathrm{do}}{ }^{\prime}$ & 0.01 & (s) \\
\hline $\mathrm{T}_{\mathrm{qo}}{ }^{\prime}$ & 0.05 & (p.u) & $\mathrm{H}$ & 2.9 & (s) \\
\hline
\end{tabular}

Table 1: Synchronous DG Specification

\section{SYNCHRONOUS GENERATOR MODELING}

The modeling of a microgrid can be done by connecting distributed generators near the load along with the main grid. The schematic diagram of a microgrid [6] is shown in Fig.1.

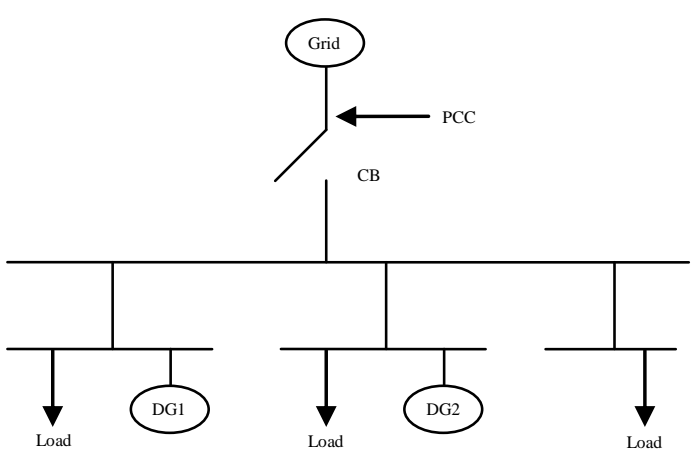

Fig. 1 Micro Grid System

A microgrid system can operate in both the Grid connected mode or islanding mode. Proper operation of these modes requires the implementation of high performance power flow control and voltage regulation algorithms. Three critical components play major role in the proper operation of microgrid in both modes. They are

$$
\begin{aligned}
& \text { - Local micro source controller } \\
& \text { - System optimizer } \\
& \text { - Distribution Protection }
\end{aligned}
$$

The modeling of the microgrid requires the construction of the synchronous generator model in both autonomous and grid connected mode. In this work the modeling of the synchronous generator has been considered and both the modes have been separately modeled for its operation. Also the interconnection of the synchronous generator with the microgrid has been simulated and analyzed using MATLAB/SIMULINK.

\subsection{Autonomous mode}

A simplified model of the synchronous generator has been developed. The considered synchronous machine has a rated power capacity of 160MVA and rated voltage of $15 \mathrm{kV}$.

\subsubsection{Electrical and mechanical sub- model of the synchronous generator:}

\section{Electrical part:}

$$
\begin{aligned}
E_{d}^{\prime} & =\frac{x_{d}^{\prime}-x_{q}}{1+s T_{q 0}^{\prime}} I_{q} \\
E_{q}^{\prime} & =\frac{x_{d}^{\prime}-x_{d}}{1+s T_{d 0}^{\prime}} I_{d}+\frac{E_{f d}}{1+s T_{d 0}^{\prime}}
\end{aligned}
$$

\section{Mechanical part:}

The system includes a turbine and governor sub-system and the blocks of the relations among rotor angle $\delta$, deviation of angular speed $\Delta \omega$, and steady state value of angular speed, $\omega 0$, as given in equation

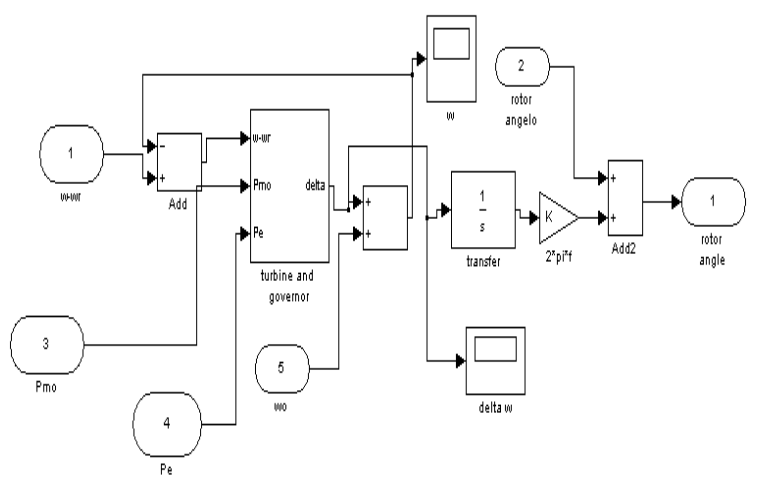

Fig. 2 Mechanical Part of the Synchronous Generator

$$
\begin{aligned}
& \Delta \omega=\frac{1}{D+s} \\
& \delta=\omega_{0} \frac{\Delta \omega}{s}
\end{aligned}
$$

\section{Turbine and governor system}

$$
\begin{aligned}
& \Delta P_{r}=\frac{K_{G}}{1+s T_{S R}} \Delta \omega \\
& \Delta P_{h}=\frac{1}{1+s T_{S M}} \Delta P_{r} \\
& \Delta P_{c}=\frac{1}{1+s T_{C H}} \Delta P_{h} \\
& \Delta P_{m}=\frac{s K_{R H} T_{R H}}{1+s T_{R H}} \Delta P_{c}
\end{aligned}
$$

\section{Exciter}

The exciter is represented by a second-order dynamical model. The sub model has two inputs, Vtr and Vt, reference and instantaneous values of terminal voltage, respectively and one output Efd in per-unit values. 


$$
\begin{aligned}
& E_{f d}=\frac{K_{E}}{1+s T_{E}}\left(V_{t r}-V_{t}-V_{s}\right) \\
& V_{s}=\frac{s K_{F}}{1+s T_{F E}} E_{f d}
\end{aligned}
$$

\section{Terminal Equations}

$$
\begin{aligned}
& V_{t d}=E_{d}^{\prime}-R_{a} I_{d}-x_{d}^{\prime} I_{q}=-V_{0} \sin \delta+R_{e} I_{d}+x_{e} I_{q} \\
& V_{t q}=E_{q}^{\prime}-R_{a} I_{q}+x_{d}^{\prime} I_{d}=-V_{0} \cos \delta+R_{e} I_{q}-x_{e} I_{d} \\
& P_{e}=E_{d}^{\prime} I_{d}+E_{q}^{\prime} I_{q}
\end{aligned}
$$

\subsubsection{Modeling at various states}

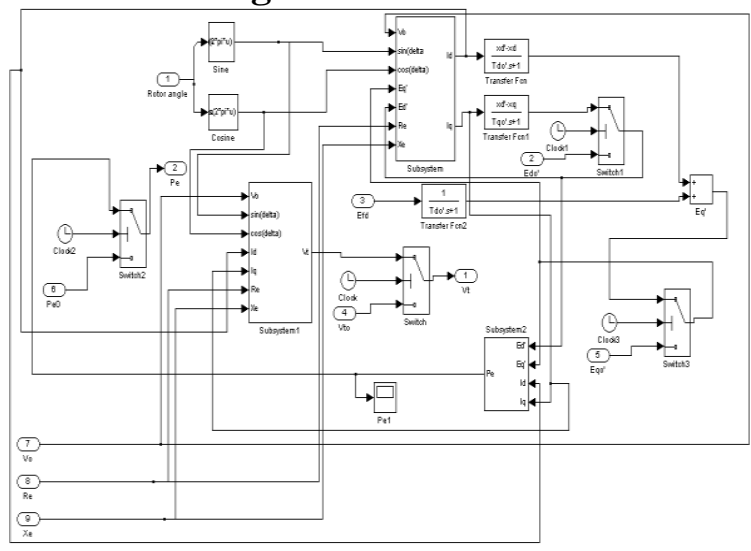

Fig. 3 Continuous Operation Model

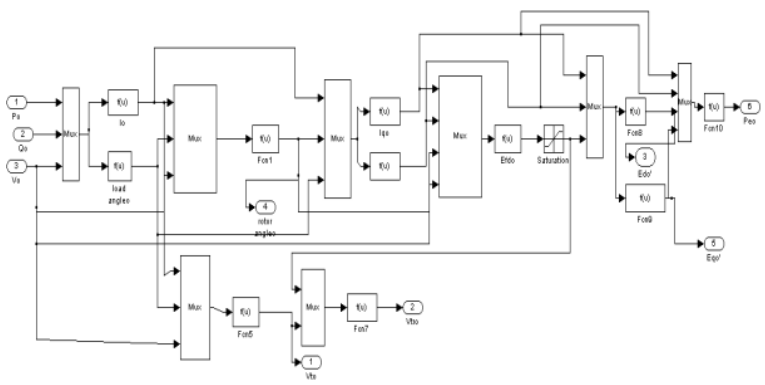

Fig. 4 Steady State Operation Model

The steady state values are calculated separately according to the block diagram of Fig. 4. The function blocks given in Fig. 4 which correspond to initial values of current, load angle, rotor angle, electromotor force in the machine, terminal voltage, real power, exciter voltage, and reference terminal voltage are calculated using the equations [7] given below:

$$
\begin{aligned}
& I_{0}=\frac{\sqrt{P_{0}^{2}+Q_{0}^{2}}}{V_{0}} \\
& \varphi_{0}=\arctan \frac{Q_{0}}{P_{0}} \\
& \delta_{0}=\arctan \frac{I_{0}\left(x_{q}+x_{e}\right) \cos \varphi_{0}-I_{0}\left(R_{a}+R_{e}\right) \sin \varphi_{0}}{V_{0}+I_{0}\left(R_{a}+R_{e}\right) \cos \varphi_{0}+I_{0}\left(x_{q}+x_{e}\right) \sin \varphi_{0}} \\
& I_{d 0}=-I_{0} \sin \left(\delta_{0}+\varphi_{0}\right)
\end{aligned}
$$

$$
\begin{aligned}
& I_{q 0}=I_{0} \cos \left(\delta_{0}+\varphi_{0}\right) \\
& E_{f d 0}=V_{0} \cos \delta_{0}+\left(R_{a}+R_{e}\right) I_{q 0}-\left(x_{d}+x_{e}\right) I_{d 0} \\
& V_{t 0}=\sqrt{\begin{array}{l}
\left(V_{0}+R_{e} I_{0} \cos \varphi_{0}+x_{e} I_{0} \sin \varphi_{0}\right)^{2} \\
+\left(x_{e} I_{0} \cos \varphi_{0}-R_{e} I_{0} \sin \varphi_{0}\right)^{2}
\end{array}} \\
& E_{d 0}^{\prime}=-\left(x_{q}-x_{d}^{\prime}\right) I_{q 0} \\
& E_{q 0}^{\prime}=E_{f d 0}+\left(x_{d}-x_{d}^{\prime}\right) I_{d 0} \\
& P_{e 0}=E_{d 0}^{\prime} I_{d 0}+E_{q 0}^{\prime} I_{q 0} \\
& P_{m 0}=P_{e 0} \\
& V_{t r}=\frac{E_{f d 0}}{K_{E}}+V_{t 0}
\end{aligned}
$$

The reference value of the terminal voltage of the synchronous machine is given in the last equation above.

\subsubsection{Complete Model}

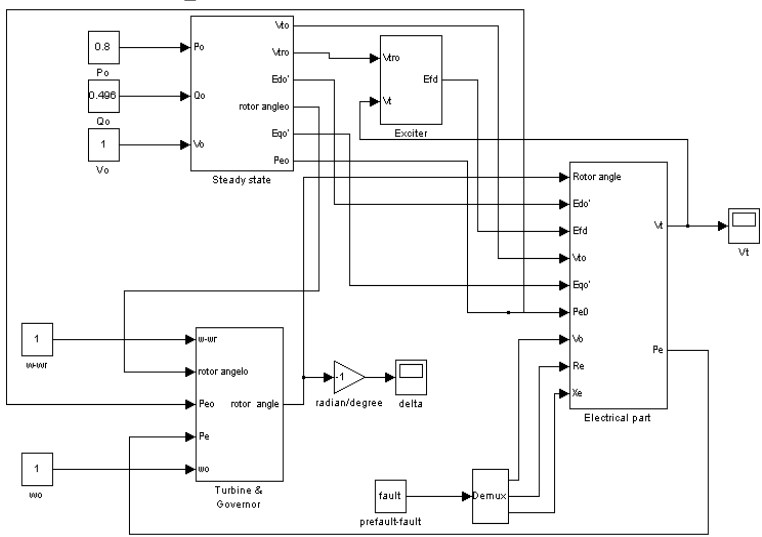

Fig. 5 Complete Model of the Synchronous Machine

\begin{tabular}{|l|l|l|l|l|l|l|l|}
\hline $\mathrm{P}_{0}$ & 0.8 & $\mathrm{x}_{\mathrm{d}}{ }^{\prime}$ & 0.245 & $\mathrm{~T}_{\mathrm{E}}$ & $0.05 \mathrm{~s}$ & $\mathrm{~T}_{\mathrm{RH}}$ & $8 \mathrm{~s}$ \\
\hline $\mathrm{Q}_{0}$ & 0.496 & $\mathrm{x}_{\mathrm{e}}$ & 0.2 & $\mathrm{~K}_{\mathrm{F}}$ & 0.025 & $\mathrm{~T}_{\mathrm{CH}}$ & $0.05 \mathrm{~s}$ \\
\hline $\mathrm{V}_{0}$ & 1 & $\mathrm{~T}_{\mathrm{d} 0}$ & $5.9 \mathrm{~s}$ & $\mathrm{~T}_{\mathrm{FE}}$ & $1 \mathrm{~s}$ & $\mathrm{~T}_{\mathrm{SR}}$ & $0.1 \mathrm{~s}$ \\
\hline $\mathrm{R}_{\mathrm{a}}$ & 0.001096 & $\mathrm{~T}_{\mathrm{q} 0}$ & $0.075 \mathrm{~s}$ & $\mathrm{D}$ & 0 & $\mathrm{~K}_{\mathrm{G}}$ & 3.5 \\
\hline $\mathrm{R}_{\mathrm{e}}$ & 0.01 & $\mathrm{~K}_{\mathrm{E}}$ & 400 & $\mathrm{M}$ & 4.74 & $\mathrm{~T}_{\mathrm{SM}}$ & $0.2 \mathrm{~s}$ \\
\hline $\mathrm{X}_{\mathrm{d}}$ & 1.7 & $\mathrm{E}_{\mathrm{fdmin}}$ & -4.5 & $\mathrm{~K}_{\mathrm{RH}}$ & 0.3 & $\omega_{\mathrm{r}}$ & 1 \\
\hline $\mathrm{X}_{\mathrm{q}}$ & 1.64 & $\mathrm{E}_{\mathrm{fdmax}}$ & 4.5 & $\omega_{0}$ & 1 & & \\
\hline
\end{tabular}

Table 2: The parameter values of the synchronous machine have a capacity of $160 \mathrm{MVA}$ rated power, $15 \mathrm{kV}$ rated voltage.

For stability analysis of a synchronous machine, it is assumed that a three-phase short-circuit at the sending terminal of one of the parallel lines has occurred at $0.6 \mathrm{~s}$ and the fault has continued until $0.78 \mathrm{~s}$. The fault is cleared by switching the faulted line between 0.78 and $0.87 \mathrm{~s}$ and then the system is returned to the pre-fault configuration [8]. These cases are represented by switch blocks in the model given in Fig. 3. 


\subsection{Grid connected mode}

The synchronous generator which has been modeled by the above said method has to be connected to the microgrid as one of the distributed generators. The connection of the synchronous generator to the microgrid as a DG will help the overall operation of the power system. Even when there is any disturbance in the main grid, the load connected to the synchronous generator can be islanded and the continuity of supply can be ensured. So it is always advantageous to connect the synchronous generator as a DG to the microgrid as it facilitates islanded operation in the power system. The interconnection of the synchronous generator with the microgrid is done by using a step up transformer, a series compensator and circuit breakers for their respective purposes as shown in fig.6. Throughout the simulation, ground resistivity is taken to be $100 \Omega \mathrm{m}$ which is practically acceptable [9].

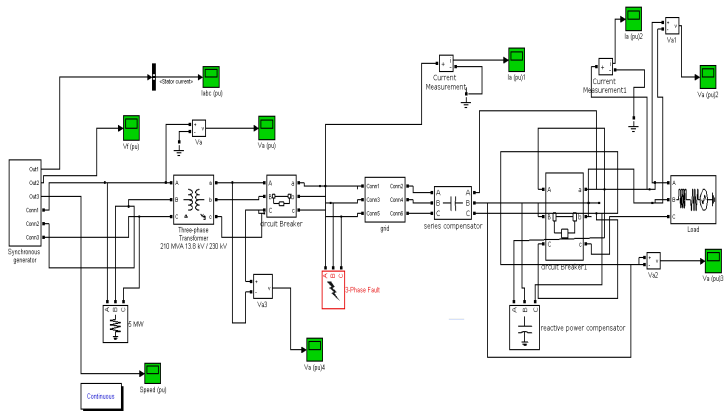

Fig. 6 Synchronous Generator connected to the grid

\section{RESULTS}

The analysis of the distributed generator was carried out and it is has been seen that the power quality is improved by connecting the load compensator with the DG to the microgrid. From Fig. 7 it has been observed that the stator voltage of the synchronous generator has many disturbances which in turn affect the stator current which has been shown in fig. 8 .

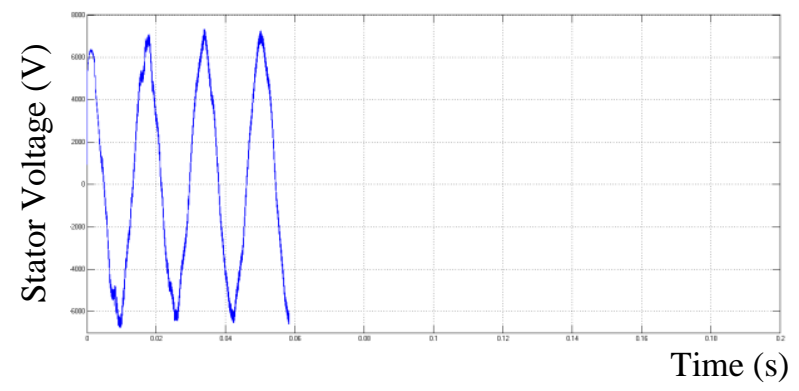

Fig. 7 Stator Voltage of the Synchronous Generator

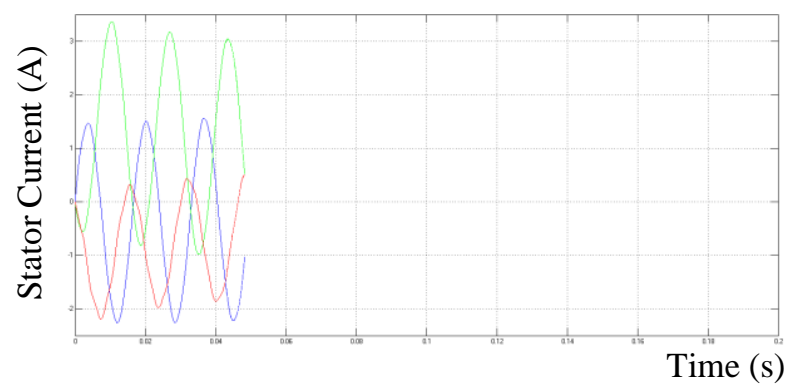

Fig. 8 Stator Current of the Synchronous Generator
During fault the harmonics are injected into the system and hence the system becomes unstable as shown in fig. 9.

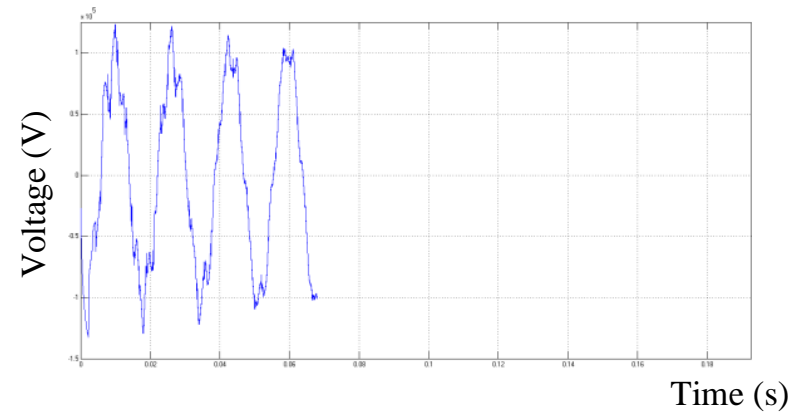

Fig. 9 Output Voltage during Fault

The microgrid is connected with a load controller and a static VAR compensator which is used to stabilize the system. The role of load controller is to exercise control over the load variations and the static VAR compensator is used to inject reactive power which brings improved stability to the system.

The voltage and current waveforms after the fault clearance with the use of load controller and static VAR compensator are shown in fig. 10 and fig. 11 respectively.

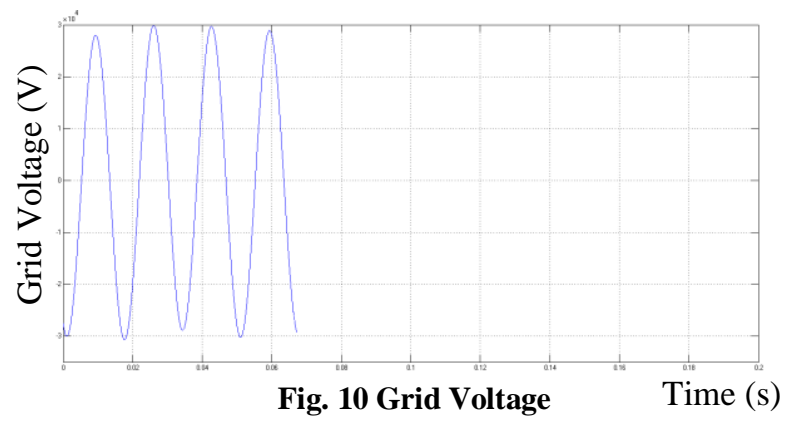

Due to connection of compensator in grid the voltage and current variations are controlled and are shown in fig. 10 and fig. 11.

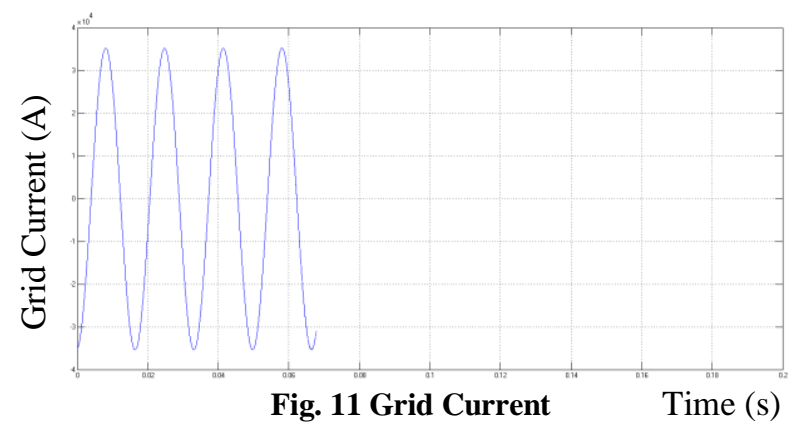

\section{CONCLUSION}

This paper focuses on the improvement of voltage stability in the distributed generation system by connecting a micro-grid with a synchronous generator to the utility grid. In this project, the modeling and analysis of synchronous generator has been done using MATLAB/SIMULINK. Also the model for connecting it to the micro grid is developed and the simulation results have been shown. We have analyzed the micro-grid by 
connecting a three phase fault to the grid. The micro-grid is analyzed in both autonomous and grid connected mode. Due to the connection of the series and shunt compensator in the microgrid, it is seen that the system is stable and there is considerable improvement in the voltage. The simulation result shows there has been considerable reduction in harmonics. It is also seen that there is tremendous improvement in the voltage stability and power quality due to the load controller and VAR compensator in both autonomous and grid connected mode.

\section{REFERENCES}

[1] Robert H Lasseter., Paolo Piagi. 2004. "Microgrid: A Conceptual Solution", Pg 20-25, PESC'04 Aachen, Germany.

[2] Juan Carlos., 2009. "Decentralized Control Techniques Applied to Electric Power Distributed Generation in Microgrids", Enginyer ýa de Sistemes, Autom`atica i Inform`atica Industrial (ESAII).

[3] Dr. Kalra, P.K., Ankit Singh Rawat., Sahay Shrey., Shashank Gupta., Sunil Meena., Piyush Choudhary. "Micro Grid Generation and Control Analysis", Pg 2 - 13 EE330 Course Project, IIT Kanpur.

[4] Paolo Piagi., Robert H Lasseter. 2006. "Autonomous Control of Microgrids", IEEE PES Meeting, Montreal.

[5] Zang, H., Chandorkar, M., Venkataramanan, G. 2003."Development of Static Switchgear for utility interconnection in a microgrid", Palm Springs, CA, Power and Energy Systems PES.
[6] Hicklin, J., Grace et al, A. 1992 . "SIMULINK, A Program for Simulating Dynamic Systems", User's Guide (MathWorks Inc.,).

[7] Zeynelgil, H.L., Demiroren, A. 1999. "The application of self-tuning control to power systems with SMES”, pg 274-278 in Proc. ELECO'99, IEEE-PES.

[8] Rahim, A.H.M.A., Mohammead, A.M. 1994. "Improvement of synchronous generator damping through superconducting magnetic energy storage systems", Pg - EC, 9 (4) IEEE Trans. (1994).

[9] Desta Zahlay Fitiwi., Rama Rao, K.S. 2009.

"Assessment of ANN-Based Auto-Reclosing Scheme Developed on Single Machine-Infinite Bus Model with IEEE 14-Bus System Model Data", TENCON 2009.

[10] Stefania Conti, Lorenzo Raffa, Umberto Vagliasindi.2009 "Analysis of Protection Issues In Autonomous MV Micro-Grids", Paper no. 0908, 20th International Conference on Electricity Distribution.

[11] Mirosław Parol, Tomasz Wójtowicz.2010 "Optimization of Exchange of Electrical Energy between Microgrid and Electricity Utility Distribution Network", Paper no. P38, MEPS'10. 